\title{
Patient perceptions of electronic medical records use and ratings of care quality
}

This article was published in the following Dove Press journal:

Patient Related Outcome Measures

2I March 2014

Number of times this article has been viewed

\author{
Lila J Finney Rutten' \\ Sana N Vieux ${ }^{2}$ \\ Jennifer L St Sauver' \\ Neeraj K Arora ${ }^{2}$ \\ Richard P Moser ${ }^{2}$ \\ Ellen Burke Beckjord ${ }^{3}$ \\ Bradford W Hesse ${ }^{2}$ \\ 'Robert D. and Patricia E. Kern \\ Center for the Science of Healthcare \\ Delivery, Department of Health \\ Sciences Research, Mayo Clinic, \\ Rochester, MN, USA; ${ }^{2}$ Division of \\ Cancer Control and Population \\ Sciences, National Cancer Institute, \\ Bethesda, MD, USA; ${ }^{3}$ Biobehavioral \\ Medicine in Oncology Program, \\ University of Pittsburgh Cancer \\ Institute, Pittsburgh, PA, USA
}

Purpose: Despite considerable potential for improving health care quality, adoption of new technologies, such as electronic medical records (EMRs), requires prudence, to ensure that such tools are designed, implemented, and used meaningfully to facilitate patient-centered communication and care processes, and better health outcomes. The association between patients' perceptions of health care provider use of EMRs and health care quality ratings was assessed. Method: Data from two iterations of the Health Information National Trends Survey, fielded in 2011 and 2012, were pooled for these analyses. The data were collected via mailed questionnaire, using a nationally representative listing of home addresses as the sampling frame $(n=7,390)$. All data were weighted to provide representative estimates of quality of care ratings and physician use of EMR, in the adult US population. Descriptive statistics, $t$-tests, and multivariable linear regression analyses were conducted.

Results: EMR use was reported significantly more frequently by females, younger age groups, non-Hispanic whites, and those with higher education, higher incomes, health insurance, and a usual source of health care. Respondents who reported physician use of EMRs had significantly higher ratings of care quality (Beta=4.83, standard error $[\mathrm{SE}]=1.7$, $P<0.01$ ), controlling for sociodemographic characteristics, usual source of health care, and health insurance status.

Conclusion: Nationally representative data suggest that patients' perceptions of EMR use are associated with their perceptions of the quality of the health care they receive.

Keywords: electronic medical records, health care quality, health information technology

\section{Introduction}

Electronic medical records (EMRs) have significant potential to facilitate information exchange and enable greater patient engagement. To maximize this potential, care must be exercised in the adoption and use of EMRs, to ensure that EMRs facilitate patient-centered communication and health care processes. ${ }^{1-5}$ Prior research exploring physicians' attitudes about EMRs ${ }^{6-9}$ and patients' satisfaction with physicians' use of EMRs has yielded mixed results. ${ }^{10-12}$ Evaluating patient perceptions of provider use of EMR and associated ratings of health care quality is a first step in understanding the impact of EMRs on the patient experience. ${ }^{13-15}$ Use of EMRs is rapidly increasing; therefore, tracking patients' perceptions of provider EMR use and assessment of their association with ratings of quality of care is important to understand patients' perspective on this evolving component of health care. ${ }^{16}$ Data from a national sample of adults in the USA were analyzed to explore whether patient-reported physician use of an EMR is associated with quality of care ratings.
Correspondence: Lila J Finney Rutten Robert D. and Patricia E. Kern Center for the Science of Healthcare Delivery, Department of Health Sciences Research, Division of Epidemiology, Mayo Clinic, 200 First Street SW, Rochester, MN 55905, USA

Tel + I 507293234 |

Fax + I 5075387957

Email rutten.lila@mayo.edu (c) (i) (5) 2014 Finney Rutten et al. This work is published by Dove Medical Press Limited, and licensed under Creative Commons Attribution - Non Commercial (unported, v3.0) permission from Dove Medical Press Limited, provided the work is properly attributed. Permissions beyond the scope of the License are administered by Dove Medical Press Limited. Information on permission from Dove Medical Press Limited, provided the work is properly attributed. P how to request permission may be found at. http://www.dovepress.com/permissions.php 


\section{Methods}

\section{Data collection and response rates}

Data from the Health Information National Trends Survey (HINTS) (HINTS 4, Cycle 1 and Cycle 2; n=7,390), a nationally representative survey of the US adult population that tracks attitudes, knowledge, and behavior relevant to health communication, were analyzed. ${ }^{17}$

HINTS 4 Cycle 1 and Cycle 2 data were collected in 2011 and 2012 via mailed questionnaires. The instruments used in these data collection efforts were cognitively tested and pilot tested to ensure respondents were able to understand and complete the instruments. ${ }^{18}$ Each instrument was also approved by the US Office of Management and Budget to ensure the level of burden for respondents was deemed acceptable. ${ }^{18}$ The sample design was a two-stage, stratified sample wherein addresses were selected from a United States Postal Service file of residential addresses, and individual respondents were selected from each sampled household. The final response rate for Cycle 1, was 36.7\% and for Cycle 2, was 40.0\%. ${ }^{19}$ Additional details about the sampling strategies and survey design for HINTS 4 are published elsewhere. ${ }^{18,20}$

\section{Measures}

\section{Ratings of health care quality}

The following question captured respondents' quality of care ratings: "Overall, how would you rate the quality of health care you received in the last 12 months?" The response options were given on a five-point scale, ranging from "excellent" to "poor." To improve interpretation, the scale was treated as interval, scores were reversed, and a linear transformation was applied to create scores ranging from $0-100$, wherein higher scores indicated higher ratings of quality.

\section{Electronic medical record use}

Respondents were asked the following question to assess whether they believed their health care provider maintained an EMR: "As far as you know, do any of your doctors or health care providers maintain your medical records in a computerized system?"

\section{Health care access}

Usual source of health care was assessed with the following: "Not including psychiatrists and other mental health professionals, is there a particular doctor, nurse, or other health professional that you see most often?" Health insurance status was assessed with the following: "Do you have any of the following health insurance or health coverage plans: Insurance through a current or former employer or union; Insurance purchased directly from an insurance company; Medicare; Medicaid, Medical Assistance, or any kind of government assistance plan for those with low incomes or disability; TRICARE [health care program for Uniformed Service members] or other military health care; VA [US Department of Vetrans' Affairs]; or Indian Health Service." Responses were recoded as "yes" or "no."

\section{Sociodemographic variables}

Sociodemographic variables included sex, age, education, race/ethnicity, annual household income, and employment.

\section{Data analyses}

SUDAAN version 10.0.1 (RTI International, Research Triangle Park, NC, USA) was used to account for the complex sample procedure. All data were weighted to provide representative estimates of the adult US population. Mean ratings of quality were calculated and compared by $t$-test for those who reported their health care providers maintain an EMR and those who reported they do not. A multivariable linear regression model was conducted, regressing health care quality ratings on a set of predictors, including sociodemographic variables, health care access, and perceived provider EMR use.

\section{Results}

The vast majority of respondents $(86.99 \%)$ reported that their health care provider maintained their medical records in a computerized system (Table 1). Significant differences in perceived EMR use were observed by health care access and sociodemographic variables. As summarized in the first data column of Table 1, perceived provider EMR use was more frequently reported by females, younger adults, non-Hispanic whites, those with higher education, higher incomes, health insurance, and a usual source of health care.

Mean ratings of quality of health care also differed by perceived EMR status, with significantly higher ratings among those reporting use of an EMR (mean $=80.9)$ compared with those reporting no use (mean $=73.6)(t=4.59, P<0.0001)$. Significantly higher ratings of quality of care were also observed among those reporting provider use of EMR compared to those reporting no EMR use for: males, females, those aged 35-64 and 65 years or older, those earning less than $\$ 50,000$ per year, Hispanics, non-Hispanic others, those with some college or less, those with health insurance, employed and unemployed persons, and those without a usual source of care (Table 2). Perceived physician use of EMR remained significantly associated with quality of care ratings in the 
Table I Weighted population estimates for perceived electronic medical record status by sociodemographic and health care access characteristics

\begin{tabular}{|c|c|c|c|c|}
\hline & \multicolumn{4}{|c|}{ Provider maintains EMR } \\
\hline & Yes $(\mathrm{N}=6,5 \mathrm{II})$ & No $(\mathrm{N}=879)$ & Chi-square & $P$-value \\
\hline Overall & $86.99 \%$ & $13.01 \%$ & & \\
\hline Health insurance & & & 42.11 & $0.0000 *$ \\
\hline Yes & 85.71 (84.60-86.76) & $60.06(54.11-65.73)$ & & \\
\hline No & $14.29(\mid 3.24-15.40)$ & $39.94(34.27-45.89)$ & & \\
\hline Regular provider & & & 63.96 & $0.0000 *$ \\
\hline Yes & $68.22(66.00-70.36)$ & $39.04(33.49-44.90)$ & & \\
\hline No & $31.78(29.64-34.00)$ & $60.96(55.10-66.5 \mathrm{I})$ & & \\
\hline Employment status & & & 0.16 & $0.694 *$ \\
\hline Employed & $55.82(53.86-57.77)$ & $57.21(50.50-63.66)$ & & \\
\hline Not employed & $44.18(42.23-46.14)$ & $42.79(36.34-49.50)$ & & \\
\hline Sex & & & 15.57 & $0.0001 *$ \\
\hline Female & $52.79(5 \mathrm{I} .97-53.6 \mathrm{I})$ & $41.34(36.55-46.30)$ & & \\
\hline Male & $47.21(46.39-48.03)$ & $58.66(53.70-63.45)$ & & \\
\hline Age & & & 5.75 & $0.0003 *$ \\
\hline $18-34$ & $30.11(29.14-31.10)$ & $34.87(29.06-41.18)$ & & \\
\hline $35-49$ & $26.36(25.67-27.06)$ & $31.42(27.13-36.06)$ & & \\
\hline $50-64$ & $25.72(25.20-26.25)$ & $22.56(19.39-26.08)$ & & \\
\hline $65-74$ & $9.73(9.42-10.05)$ & $5.64(4.22-7.49)$ & & \\
\hline$\geq 5+$ & $8.08(7.78-8.39)$ & $5.5 \mathrm{I}(4.02-7.5 \mathrm{I})$ & & \\
\hline Income & & & 8.38 & $0.0000 *$ \\
\hline$<\$ 20,000$ & $21.40(19.56-23.36)$ & $32.88(26.49-39.97)$ & & \\
\hline$\$ 20,000$ to $<\$ 35,000$ & $15.90(\mid 4.39-17.53)$ & $16.5 \mid(\mid 2.69-21.20)$ & & \\
\hline$\$ 35,000$ to $<\$ 50,000$ & $14.47(\mid 3.26-15.76)$ & $13.63(9.54-19.11)$ & & \\
\hline$\$ 50,000$ to $<\$ 75,000$ & $16.55(14.80-18.46)$ & 19.30 (14.67-24.98) & & \\
\hline$\$ 75,000$ to $<\$ 100,000$ & I2.45 (|I.29-|3.7I) & $7.49(5.4 I-10.28)$ & & \\
\hline$\$ 100,000$ or more & $19.24(17.72-20.85)$ & $10.18(7.86-13.09)$ & & \\
\hline Race/ethnicity & & & 8.20 & $0.0000 *$ \\
\hline Hispanic & $12.30(11.52-13.12)$ & $23.34(18.68-28.76)$ & & \\
\hline NH White & $65.30(64.23-66.37)$ & $48.26(43.09-53.46)$ & & \\
\hline NH Black & $9.89(9.29-10.53)$ & $13.87(10.49-18.12)$ & & \\
\hline $\mathrm{NH}$ Other & $6.41(5.85-7.02)$ & $9.32(6.31-13.56)$ & & \\
\hline Missing & $6.10(5.35-6.93)$ & $5.21(3.96-6.82)$ & & \\
\hline Education & & & 7.49 & $0.0001 *$ \\
\hline Less than high school & $11.79(10.80-12.86)$ & $22.68(18.01-28.14)$ & & \\
\hline High school graduate & $20.98(19.68-22.34)$ & $24.63(19.62-30.44)$ & & \\
\hline Some college & 35.21 (33.74-36.7I) & $29.87(24.48-35.87)$ & & \\
\hline College graduate & $32.02(31.07-32.99)$ & $22.83(19.17-26.95)$ & & \\
\hline
\end{tabular}

Note: *Significant $P$-value.

Abbreviations: EMR, electronic medical record; $\mathrm{NH}$, non-Hispanic.

multivariable model. Respondents who reported physician use of EMR had significantly higher ratings of care quality (Beta $=4.83$, standard error $[\mathrm{SE}]=1.70, P<0.01$ ). Having a usual source of health care, increasing age, and higher income were also significantly associated with higher ratings of care quality, in the multivariable model (Table 3).

\section{Discussion}

Despite their considerable potential for improving health care quality, adoption of health information technologies, such as EMRs requires prudence, to ensure that such tools are designed, implemented, and used meaningfully to facilitate patient-centered care processes and improved health outcomes. ${ }^{1,21,22} \mathrm{We}$ assessed patients' perceptions of EMR use and associated ratings of quality. Our analyses revealed that the majority of the population believes that their health care providers maintain an EMR. This estimate is strikingly higher than the estimated $55 \%$ of a national sample of physicians who reported EMR use in 2011, and somewhat higher than the estimated $69 \%$ of physicians who reported EMR use in 2012. ${ }^{16,23}$ It is important to bear in mind that the adoption of an EMR varies significantly by type of clinical practice. For example, data from the National Ambulatory Medical Care Survey (NAMCS) Physician 
Table 2 Weighted mean health care quality ratings by electronic medical record status

\begin{tabular}{|c|c|c|c|c|c|c|}
\hline & \multicolumn{6}{|c|}{ Mean rating of health care quality on a 100 point scale (higher score $=$ greater quality) } \\
\hline & \multicolumn{2}{|c|}{$\begin{array}{l}\text { Provider uses EMR } \\
(\mathrm{N}=6,5 \mathrm{II})\end{array}$} & \multicolumn{2}{|c|}{$\begin{array}{l}\text { Provider does not use } \\
\text { EMR }(\mathrm{N}=879)\end{array}$} & \multirow[t]{2}{*}{ t-test } & \multirow[t]{2}{*}{$P$-value } \\
\hline & $\overline{\mathbf{N}}$ & Mean (SE) & $\mathbf{N}$ & Mean (SE) & & \\
\hline Overall & 6,511 & $80.92(0.47)$ & 879 & $73.64(1.57)$ & 4.59 & $0.0000 *$ \\
\hline \multicolumn{7}{|l|}{ Health insurance } \\
\hline Yes & 5,107 & $81.59(0.47)$ & 480 & $75.37(1.92)$ & 3.16 & $0.0021 *$ \\
\hline No & 456 & $75.49(1.74)$ & 79 & $68.18(4.02)$ & 1.72 & 0.0893 \\
\hline \multicolumn{7}{|l|}{ Regular provider } \\
\hline Yes & 4,392 & $82.85(0.49)$ & 359 & $80.21(1.68)$ & 1.56 & 0.1223 \\
\hline No & 1,159 & $75.17(1.26)$ & 194 & $65.81(2.90)$ & 3.05 & $0.0030 *$ \\
\hline \multicolumn{7}{|l|}{ Employment status } \\
\hline Employed & 2,760 & $80.15(0.59)$ & 268 & $74.50(2.15)$ & 2.57 & $0.0118 *$ \\
\hline Not employed & 2,624 & $81.92(0.80)$ & 280 & $73.09(2.09)$ & 3.9 & $0.0002 *$ \\
\hline \multicolumn{7}{|l|}{ Sex } \\
\hline Female & 3,417 & $81.08(0.60)$ & 316 & $74.24(1.65)$ & 4.09 & $0.0001 *$ \\
\hline Male & $2,07 \mid$ & $80.87(0.75)$ & 232 & $73.42(2.56)$ & 2.83 & $0.0056 *$ \\
\hline \multicolumn{7}{|l|}{ Age } \\
\hline $18-34$ & 768 & $78.98(1.34)$ & 87 & $72.23(3.89)$ & 1.65 & $0.1025^{*}$ \\
\hline $35-49$ & 1,243 & $79.36(0.72)$ & 132 & $72.66(2.88)$ & 2.30 & $0.0234 *$ \\
\hline $50-64$ & 1,899 & $81.84(0.64)$ & 190 & $74.36(2.00)$ & 3.68 & $0.0004 *$ \\
\hline $65-74$ & 902 & $85.07(0.76)$ & 78 & $80.05(3.60)$ & 1.35 & 0.1800 \\
\hline$\geq 75$ & 685 & $84.49(0.89)$ & 63 & $73.65(3.94)$ & 2.69 & $0.0084 *$ \\
\hline \multicolumn{7}{|l|}{ Income } \\
\hline$<\$ 20,000$ & 1,157 & $76.98(1.44)$ & 160 & $70.23(3.02)$ & 2.03 & $0.0453 *$ \\
\hline$\$ 20,000$ to $<\$ 35,000$ & 861 & $79.86(1.26)$ & 91 & $68.82(3.37)$ & 3.32 & $0.0013 *$ \\
\hline$\$ 35,000$ to $<\$ 50,000$ & 820 & $82.05(1.10)$ & 68 & $74.13(3,29)$ & 2.27 & $0.0253 *$ \\
\hline$\$ 50,000$ to $<\$ 75,000$ & 903 & $82.69(0.82)$ & 106 & $76.17(3.4 I)$ & 1.88 & 0.0625 \\
\hline$\$ 75,000$ to $<\$ 100,000$ & 690 & $81.85(0.95)$ & 50 & $78.55(3.06)$ & 0.99 & 0.3244 \\
\hline$\$ 100,000$ or more & 1,046 & $83.64(0.87)$ & 72 & $78.64(4.21)$ & 1.17 & 0.2433 \\
\hline \multicolumn{7}{|l|}{ Race/ethnicity } \\
\hline Hispanic & 604 & $78.70(1.95)$ & 103 & $68.11(2.09)$ & 4.27 & $0.0000 *$ \\
\hline NH White & 3,515 & $81.66(0.58)$ & 263 & $78.24(1.94)$ & 1.77 & 0.0799 \\
\hline NH Black & 767 & $78.19(1.08)$ & 109 & $69.89(5.79)$ & 1.38 & 0.1709 \\
\hline NH Other & 319 & 83.18 (1.82) & 43 & $64.04(5.39)$ & 3.35 & $0.0012 *$ \\
\hline Missing & 391 & $79.10(1.81)$ & 46 & $73.57(4.93)$ & 1.02 & 0.3110 \\
\hline \multicolumn{7}{|l|}{ Education } \\
\hline Less than high school & 467 & $78.66(1.47)$ & 91 & $68.02(3.35)$ & 3.08 & $0.0026 *$ \\
\hline High school graduate & 1,104 & $81.67(0.93)$ & $13 \mid$ & $73.02(3.27)$ & 2.50 & $0.0139 *$ \\
\hline Some college & 1,664 & $81.42(0.92)$ & 138 & $74.94(3.11)$ & 1.99 & $0.0496 *$ \\
\hline College graduate & 2,264 & $80.83(0.65)$ & 191 & $78.23(I .8 I)$ & 1.37 & 0.1734 \\
\hline
\end{tabular}

Note: *Significant $P$-value.

Abbreviations: EMR, electronic medical record; $\mathrm{NH}$, non-Hispanic; SE, standard error.

Workflow mail survey showed adoption of an EMR to be as low as $29 \%$ among solo practitioners to as high as $100 \%$ in health maintenance organizations, with increasing adoption and use of EMRs with increasing practice size. ${ }^{16}$ With the movement toward group practice, fewer patients are receiving care in the types of care settings that are least likely to have adopted EMRs and increasing numbers of patients are receiving care from the types of settings that are most likely to maintain EMRs. ${ }^{16,24,25}$ Therefore, the estimates of EMR use obtained in our data may, in part, be a reflection of greater numbers of patients being seen in the larger group model and health maintenance organizations that are more likely to maintain EMRs, although we are not able to discern this from our data.

The higher ratings of quality of care observed among those who reported physician use of EMR, even after controlling for important sociodemographic and health care access variables, underline the potential importance of perceived EMR use on the patient-clinician encounter. Furthermore, among persons without a usual source of care, ratings of quality of care were significantly higher for those who reported that their health care provider maintained an EMR compared with those who reported that they did not, while no differences were observed among persons with a usual 
Table 3 Independent associations of electronic medical record use and quality of care ratings

\begin{tabular}{|c|c|c|c|c|}
\hline \multirow[t]{2}{*}{$n=5,576$} & \multicolumn{4}{|c|}{ Quality of care ratings } \\
\hline & $\begin{array}{l}\text { Beta } \\
\text { coefficient }\end{array}$ & $\begin{array}{l}\text { SE } \\
\text { beta }\end{array}$ & $\begin{array}{l}\text { Adj } \\
\text { Wald } F\end{array}$ & $P$-value \\
\hline Provider uses EMR & & & 8.05 & $0.0055^{*}$ \\
\hline Yes & 4.83 & 1.70 & & \\
\hline No & 0.00 & 0.00 & & \\
\hline Health insurance & & & 0.95 & 0.3319 \\
\hline Yes & 1.84 & 1.88 & & \\
\hline No & 0.00 & 0.00 & & \\
\hline Regular provider & & & $24.6 \mathrm{I}$ & $0.0000 *$ \\
\hline Yes & 6.63 & 1.34 & & \\
\hline No & 0.00 & 0.00 & & \\
\hline Employment status & & & 2.61 & 0.1092 \\
\hline Employed & 0.00 & 0.00 & & \\
\hline Not employed & 1.76 & 1.09 & & \\
\hline Sex & & & 0.16 & 0.6885 \\
\hline Female & 0.37 & 0.91 & & \\
\hline Male & 0.00 & 0.00 & & \\
\hline Age & & & 3.07 & $0.0200 *$ \\
\hline $18-34$ & -3.09 & 1.78 & & \\
\hline $35-49$ & -4.80 & 1.69 & & \\
\hline $50-64$ & -2.71 & 1.44 & & \\
\hline $65-74$ & -0.38 & 1.19 & & \\
\hline$\geq 75$ & 0.00 & 0.00 & & \\
\hline Income & & & 3.57 & $0.0053^{*}$ \\
\hline$<\$ 20,000$ & 0.00 & 0.00 & & \\
\hline$\$ 20,000$ to $<\$ 35,000$ & 2.40 & 1.96 & & \\
\hline$\$ 35,000$ to $<\$ 50,000$ & 5.17 & 1.95 & & \\
\hline$\$ 50,000$ to $<\$ 75,000$ & 6.01 & 1.92 & & \\
\hline$\$ 75,000$ to $<\$ 100,000$ & 5.34 & 1.87 & & \\
\hline$\$ 100,000$ or more & 7.17 & 1.87 & & \\
\hline Race/ethnicity & & & 0.58 & 0.6767 \\
\hline NH White & 0.00 & 0.00 & & \\
\hline Hispanic & -1.36 & 2.12 & & \\
\hline NH Black & -1.48 & 1.58 & & \\
\hline $\mathrm{NH}$ other & 1.83 & 2.08 & & \\
\hline Missing & -0.50 & 1.98 & & \\
\hline Education & & & 2.40 & 0.0726 \\
\hline Less than high school & 0.00 & 0.00 & & \\
\hline High school graduate & 2.57 & 1.84 & & \\
\hline Some college & 1.78 & 1.99 & & \\
\hline College graduate & 0.01 & 1.88 & & \\
\hline
\end{tabular}

Note: *Significant $P$-value.

Abbreviations: EMR, electronic medical record; $\mathrm{NH}$, non-Hispanic; $\mathrm{SE}$, standard error.

source of care. Prior research indicates that persons without a usual source of care are less likely to use preventive services, more likely to rate their care unfavorably, more likely to use emergency services, and more likely to experience poor health outcomes. ${ }^{26-31}$ Although not directly discernible from the HINTS data, this finding may suggest that EMRs play a role in continuity of care for those who lack a regular provider. Further research is needed to explore the ways in which EMR capabilities and health information exchange efforts can better support continuity of care, particularly for patients without a usual source of care.

HINTS data are derived from cross-sectional surveys, therefore inferences about causality in observed relationships are not appropriate. The response rate for this survey, although an improvement over declining response rates from telephone surveys, is low. ${ }^{32,33}$ Low response rates can lead to biases in the data. However, significant efforts were made in this data collection to reduce the potential for bias, through modality coverage and sampling. ${ }^{34}$ Additionally, recent methodological research suggests that the potential for bias resulting from declining response rates may be less significant than previously assumed..$^{33,35,36}$

National survey tools are often constrained by survey length and respondent burden to measuring constructs of interest with only one or two items. In particular, the oneitem measure of provider EMR use is relatively blunt, may not elicit accurate reports from respondents, and may fail to capture the functionality and nature of EMRs that may contribute to various aspects of care quality. Although the EMR question followed a series of questions on patient health care experiences that encouraged respondents to consider the health care providers that they had seen in the prior year, it was a broadly stated question and not specific to any one health care provider. A final limitation to note is that the association of perceived provider EMR use and ratings of quality may be confounded by the potential for practices with greater resources to have functioning EMR systems. That is, it may be the case that the greater resources of practices with EMR systems may be the driving factor in patient ratings of quality rather than the EMR itself. This, however, was not assessed and therefore could not be controlled in the analyses.

\section{Conclusion}

Our analyses revealed higher ratings of general care quality among patients who believed their health care providers maintained an EMR, providing early evidence, from the patient perspective, of a positive evaluation of "meaningful use" of information technology in the health care setting. While EMRs have the potential to facilitate information exchange, enable greater patient engagement, and improve continuity of care, caution must be exercised in adoption and use of EMRs to ensure these tools facilitate, rather than impede, patient-centered communication and care processes. ${ }^{5}$ Understanding the patient perspective on use of EMR and associated ratings of health care quality is a first step in evaluating the impact of EMRs on the patient experience. ${ }^{13-15}$ Continued research is needed to track the impact of EMRs on the patient experience, patient-reported outcomes, care 
processes, and health outcomes and to evaluate specific use of EMR functionality to improve patient care.

\section{Disclosure}

The authors report no conflicts of interest in this work.

\section{References}

1. Krist AH, Woolf SH. A vision for patient-centered health information systems. JAMA. 2011;305(3):300-301.

2. Bates DW, Bitton A. The future of health information technology in the patient-centered medical home. Health Aff (Millwood). 2010;29(4): 614-621.

3. Blumenthal D. Launching HITECH. N Engl J Med. 2010;362(5): 382-385.

4. Blumenthal D, Tavenner M. The "meaningful use" regulation for electronic health records. $N$ Engl J Med. 2010;363(6):501-504.

5. Snyder CF, Wu AW, Miller RS, Jensen RE, Bantug ET, Wolff AC. The role of informatics in promoting patient-centered care. Cancer $J$. 2011;17(4):211-218.

6. McGuire MJ, Noronha G, Samal L, Yeh HC, Crocetti S, Kravet S. Patient safety perceptions of primary care providers after implementation of an electronic medical record system. J Gen Intern Med. 2013;28(2): 184-192.

7. Terry AL, Brown JB, Bestard Denomme L, Thind A, Stewart M. Perspectives on electronic medical record implementation after two years of use in primary health care practice. J Am Board Fam Med. 2012;25(4):522-527.

8. Abramson EL, Patel V, Malhotra S, et al. Physician experiences transitioning between an older versus newer electronic health record for electronic prescribing. Int J Med Inform. 2012;81(8):539-548.

9. Lau F, Price M, Boyd J, Partridge C, Bell H, Raworth R. Impact of electronic medical record on physician practice in office settings: a systematic review. BMC Med Inform Decis Mak. 2012;12:10.

10. Liu J, Luo L, Zhang R, Huang T. Patient satisfaction with electronic medical/health record: a systematic review. Scand J Caring Sci. 2013;27(4):785-791.

11. Solomon GL, Dechter M. Are patients pleased with computer use in the examination room? J Fam Pract. 1995;41(3):241-244.

12. Rozenblum R, Donzé J, Hockey PM, et al. The impact of medical informatics on patient satisfaction: a USA-based literature review. Int J Med Inform. 2013;82(3):141-158.

13. Beckjord EB, Rechis R, Nutt S, Shulman L, Hesse BW. What do people affected by cancer think about electronic health information exchange? Results From the 2010 LIVESTRONG Electronic Health Information Exchange Survey and the 2008 Health Information National Trends Survey. J Oncol Pract. 2011;7(4):237-241.

14. Atienza AA, Hesse BW, Gustafson DH, Croyle RT. E-health research and patient-centered care examining theory, methods, and application. Am J Prev Med. 2010;38(1):85-88.

15. Hesse BW, Shneiderman B. eHealth research from the user's perspective. Am J Prev Med. 2007;32(Suppl 5):S97-S103.

16. Jamoom E, Beatty P, Bercovitz A, Woodwell D, Palso K, Rechtsteiner E. Physician Adoption of Electronic Health Record Systems: United States, 2011. Atlanta, GA: Centers for Disease Control and Prevention/National Center for Health Statistics; 2012. Available from: http://www.cdc.gov/ nchs/data/databriefs/db98.htm. Accessed January 17, 2014.

17. Nelson DE, Kreps GL, Hesse BW, et al. The Health Information National Trends Survey (HINTS): development, design, and dissemination. J Health Commun. 2004;9(5):443-460; discussion 81-84.

18. Westat. Health Information National Trends Survey 4 (HINTS 4): Cycle 2 Methodology Report. Rockville, MD: Westat; 2013.
19. American Association for Public Opinion Research (AAPOR). Standard Definitions: Final Dispositions of Case Codes and Outcome Rates for Surveys. 7th ed. Deerfield, IL: American Association for Public Opinion Research; 2011.

20. Finney Rutten LJ, Davis T, Beckjord EB, Blake K, Moser RP, Hesse BW. Picking up the pace: changes in method and frame for the health information national trends survey (2011-2014). J Health Commun. 2012;17(8):979-989.

21. Ahern DK, Woods SS, Lightowler MC, Finley SW, Houston TK. Promise of and potential for patient-facing technologies to enable meaningful use. Am J Prev Med. 2011;40(5 Suppl 2):S162-S172.

22. Hesse BW, Hanna C, Massett HA, Hesse NK. Outside the box: will information technology be a viable intervention to improve the quality of cancer care? J Natl Cancer Inst Monogr. 2010;2010(40):81-89.

23. Schoen C, Osborn R, Squires D, et al. A survey of primary care doctors in ten countries shows progress in use of health information technology, less in other areas. Health Aff (Millwood). 2012;31(12):2805-2816.

24. ncsl.org [homepage on the Internet]. Managed care, market reports and the States. National Conference of State Legislature (NCSL); 2011 [updated Jun 2013; cited August 28, 2012]. Available from: http:// www.ncsl.org/issues-research/health/managed-care-and-the-states. aspx. Accessed January 17, 2014.

25. healthcarefinancenews.com [homepage on the Intranet]. MGMA: 65 percent of established doctors are in hospital-owned practices. Healthcare Finance News (HIMSS Media); 2010. Available from: http:// www.healthcarefinancenews.com/news/mgma-65-percent-establisheddoctors-are-hospital-owned-practices. Accessed January 17, 2014.

26. DeVoe JE, Fryer GE, Phillips R, Green L. Receipt of preventive care among adults: insurance status and usual source of care. Am J Public Health. 2003;93(5):786-791.

27. DeVoe JE, Saultz JW, Krois L, Tillotson CJ. A medical home versus temporary housing: the importance of a stable usual source of care. Pediatrics. 2009;124(5):1363-1371.

28. DeVoe JE, Tillotson CJ, Lesko SE, Wallace LS, Angier H. The case for synergy between a usual source of care and health insurance coverage. J Gen Intern Med. 2011;26(9):1059-1066.

29. DeVoe JE, Tillotson CJ, Wallace LS, Angier H, Carlson MJ, Gold R. Parent and child usual source of care and children's receipt of health care services. Ann Fam Med. 2011;9(6):504-513.

30. DeVoe JE, Tillotson CJ, Wallace LS, Lesko SE, Pandhi N. Is health insurance enough? A usual source of care may be more important to ensure a child receives preventive health counseling. Matern Child Health J. 2012;16(2):306-315.

31. DeVoe JE, Wallace LS, Pandhi N, Solotaroff R, Fryer GE Jr. Comprehending care in a medical home: a usual source of care and patient perceptions about healthcare communication. J Am Board Fam Med. 2008;21(5):441-450.

32. Blumberg SJ, Luke JV, Cynamon ML. Telephone coverage and health survey estimates: evaluating the need for concern about wireless substitution. Am J Public Health. 2006;96(5):926-931.

33. Fahimi M, Link M, Mokdad A, Schwartz DA, Levy P. Tracking chronic disease and risk behavior prevalence as survey participation declines: statistics from the behavioral risk factor surveillance system and other national surveys. Prev Chronic Dis. 2008;5(3):A80.

34. Cantor D, Coa K, Crystal-Mansour S, Davis T, Dipko S, Sigman R. Health Information National Trends Survey (HINTS) 2007. Rockville, MD: Westat; 2009.

35. Gentry EM, Kalsbeek WD, Hogelin GC, et al. The behavioral risk factor surveys: II. Design, methods, and estimates from combined state data. Am J Prev Med. 1985;1(6):9-14.

36. Nelson DE, Powell-Griner E, Town M, Kovar MG. A comparison of national estimates from the National Health Interview Survey and the Behavioral Risk Factor Surveillance System. Am J Public Health. 2003;93(8):1335-1341. 
Patient Related Outcome Measures

Dovepress

\section{Publish your work in this journal}

Patient Related Outcome Measures is an international, peer-reviewed, open access journal focusing on treatment outcomes specifically relevant to patients. All aspects of patient care are addressed within the journal and practitioners from all disciplines are invited to submit their work as well as healthcare researchers and patient support groups.

Submit your manuscript here: http://www.dovepress.com/patient-related-outcome-measures-journal
The manuscript management system is completely online and includes a very quick and fair peer-review system. Visit http://www.dovepress. com/testimonials.php to read real quotes from published authors. 